\title{
A Mathematical Model of the Drag Component of a Sprinkler Spray Adjacent to Horizontal Smoke Vents
}

\author{
K. Y. LI* AND M. J. SPEARPOINT \\ Department of Civil and Natural Resources Engineering \\ University of Canterbury, Christchurch 8140, New Zealand \\ J. Ji, R. HuO, Y. Z. LI AND L. H. Hu \\ State Key Laboratory of Fire Science, University of Science \\ and Technology of China, Hefei 230027, China
}

\begin{abstract}
A mathematical model has been developed to investigate the effect of a sprinkler spray on adjacent horizontal smoke venting and in particular the water droplet drag component. The pressure difference across a roof vent and the volumetric flow of smoke vented are determined by considering the interaction between the drag force of the sprinkler spray and the buoyancy of the smoke layer in the spray region. Smoke venting may become progressively more inefficient as the sprinkler operating pressure increases due to the cooling and drag effect of the sprinkler spray. Full scale experiments were carried out to validate the model. Results show that the mathematical model can predict the observed trend of a decrease in vented volumetric flow with an increase in sprinkler operating pressure, which eventually leads to ineffective smoke venting. Experiments with different smoke venting areas show that vent area has little influence on smoke flow once sprinkler pressure causes a loss in smoke flow efficiency or vent function.
\end{abstract}

KEY WORDS: Sprinkler spray, smoke venting, spray venting interaction.

\section{INTRODUCTION}

T HE IMPORTANCE OF sprinklers as a tool in fire safety building design is universally recognized. Sprinklers are installed in many buildings such as hotels, factories and shopping malls around the world. It is also well recognized that smoke and heat vents can play an important role in the fire

*Author to whom correspondence should be addressed. Email: kai-yuan.li@canterbury.ac.nz

Journal of Fire Protection Engineering, Vol. 00-Month 2010

1042-3915/10/00 0001-28 \$10.00/0ＯDOI: 10.1177/1042391509360270

(C) Society of Fire Protection Engineers 2009

SAGE Publications, Los Angeles, London, New Delhi and Singapore 
safety design of buildings [1,2]. However the buoyancy of the hot smoke layer, which drives natural smoke venting through horizontal (roof) openings, may decrease due to the cooling effect of the water spray after sprinkler activation. The drag force produced by the water droplets also has the potential to pull the stratified smoke layer downward. These two factors can lead to a decrease in smoke venting efficiency. Under such conditions, smoke may remain in a building, which could be a risk to evacuation and fire fighting [3-5].

There has been a long-standing debate in the fire protection community about the combined use of roof smoke vents/draft curtains and sprinklers $[4,5]$. The reports in favor of combined use of the two systems usually claim that smoke vents can exhaust the combustion products, decrease the number of operating sprinklers, help the fire service identify the fire location and reduce the building temperature while the sprinklers are inoperative. However, others have claimed that smoke vents will enhance burning rate and delay the activation of sprinklers and that the combined use is not cost effective as smoke venting may lose its benefits with sprinkler operation. So far, the designs of sprinklers and roof vents have remained independent of each other [6-8] and a broadly accepted design application for both sprinklers and vents has not been universally recognized [8]. Even though numerous studies have been conducted over the past few decades, many questions about the interaction of these devices have yet to be resolved.

FMRC conducted a full scale experimental study [9] in 1956 to investigate the interaction of sprinklers, vents and draft curtains which showed that draft curtains may reduce the number of operating sprinklers to only those within the curtained space and smoke vents have little effect on sprinkler operation but are very important for keeping smoke flowing out to an adjacent curtained space. In the 1960's, research work by Thomas and Hinkley [10] on the performance of roof vents led to a tentative recommendation that sprinklers should operate before vents in order to avoid the delay caused by smoke venting. Since then, large scale experiments have been conducted by Suchomel [11], Waterman et al. [12], Hinkley et al. [13], Sheppard and Steppan [14] and McGrattan et al. [5] to investigate the interaction between sprinklers and smoke vents. Numerical work on the interaction of roof vents and sprinklers has also been studied by Heselden [15], Hinkley [16,17], Chow and Cheung [18], McGrattan et al. [5] and Cooper $[19,20]$. However most of these experimental and numerical studies focused on how roof vents affect the activation time, number, and location of operating sprinklers; or how sprinklers affect the activation time and number of operating automatic roof vents. In contrast, little effort has been placed on studying the effect of sprinklers on smoke venting.

The work conducted at SP [21,22] in 1992 included experiments designed to measure the effect of a single sprinkler on the temperature and velocity of 
the hot smoke flowing through a $1 \mathrm{~m} \times 2 \mathrm{~m}$ ceiling vent located in a $7.5 \mathrm{~m} \times 15 \mathrm{~m} \times 6 \mathrm{~m}$ high channel-like space that was open on two sides. A single sprinkler with a flow of either 80 or $100 \mathrm{~L} / \mathrm{min}$ was installed at various locations at the ceiling. The conclusions drawn were that when the sprinkler was installed between the fire and the vent, it had a 'significant' impact on the discharge rate of the vent and when the sprinkler was installed downstream of the vent its influence on vent discharge was regarded as 'negligible'. The SP experiments mainly focused on discharge efficiency of the vent far away from the sprinkler which was mainly determined by the thickness and the temperature of the smoke layer beneath the vent instead of the drag force of sprinkler spray. The effect of roof vents adjacent to a sprinkler spray was experimentally studied by McGrattan et al. [5] with a velocity probe positioned at the center of the vents. Experiments were conducted on a $37 \mathrm{~m} \times 37 \mathrm{~m}$ ceiling with a height of $7.6 \mathrm{~m}$. One $1.2 \mathrm{~m} \times 2.4 \mathrm{~m}$ natural smoke vent was installed among 49 sprinklers on $3 \mathrm{~m} \times 3 \mathrm{~m}$ spacing. The vent could be operated manually or automatically to extract the hot smoke. Unfortunately, the velocity data was deemed to be unreliable by the researchers and there was no means to directly measure the discharge rate of smoke venting in those experiments.

Before the work on sprinkler spray characteristics by Sheppard [23], it was difficult to model mathematically the drag force of droplets and therefore analyze the effect of a sprinkler spray on smoke venting. Now, the volumetric flow of smoke through a roof vent adjacent to a sprinkler can be predicted by considering smoke layer thickness, smoke layer temperature and sprinkler operating pressure. Full scale experiments were carried out to validate the mathematical model. Since this article focuses on the drag effect, cooling effects are not analyzed in detail. Instead, the cooling effect of the sprinkler droplets on the smoke flow has been accounted for by the temperature decrease measured during the full-scale experiments presented in this article.

\section{MATHMATICAL MODEL}

\section{Assumptions}

Several assumptions are required to develop the mathematical model. They are as follows:

(1) The smoke layer beneath the roof vent is pulled down by the drag force of the sprinkler spray droplets and at the same time pushed back up by its own buoyancy. If the drag force is stronger than buoyancy, no smoke can flow out through the roof vent. 


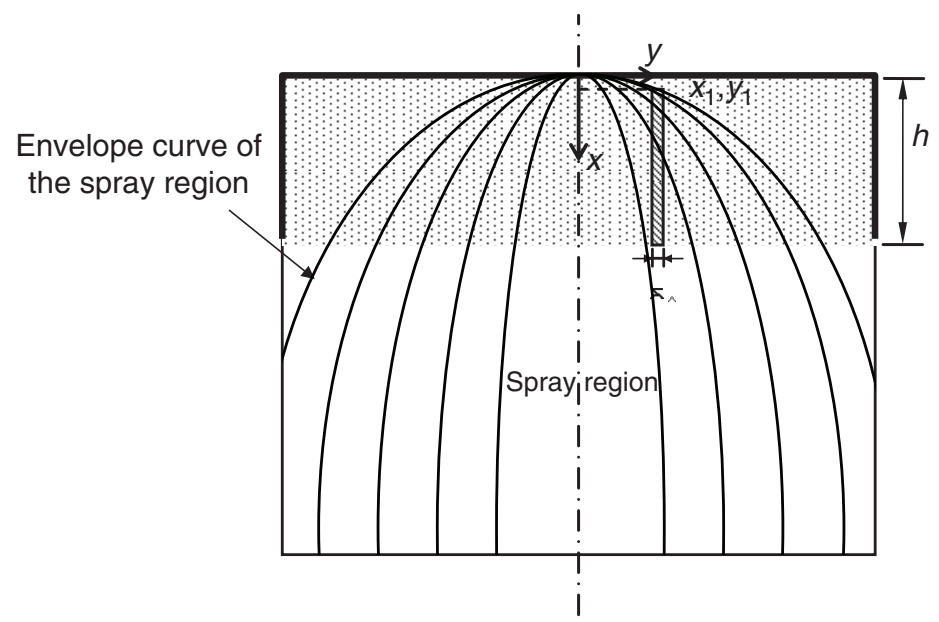

Figure 1. Schematic view of drag force on smoke layer column element.

(2) The effect of sprinkler spray on the smoke layer beneath the roof vent is considered by taking a column element of the smoke layer whose base area is unit $\delta \Delta$ and with fixed height $h$, which is $x_{1}$, as shown in Figure 1.

(3) The drag force of sprinkler spray is mainly caused by the vertical component of droplet velocity and as a result the horizontal velocity component is not considered.

(4) The water flow density distribution in a horizontal cross section of the sprinkler spray is uniform.

(5) Small oscillations of smoke layer interface are not considered, although they were observed in the experiments.

\section{Drag Force of the Sprinkler Spray Droplets}

As shown in Figure 1, the darkened region of the smoke layer is that which is affected by the spray. The initial thickness of the smoke layer is $h$. The initial velocity of the smoke layer in all directions is assumed to be zero. The vertical drag force caused by a spray droplet is then expressed as [24,25]

$$
\begin{gathered}
D(x)=k_{d} v^{2} \\
k_{d}=\frac{\rho_{g}(x) C_{D} A_{d}}{2}
\end{gathered}
$$

and $C_{D}$ is assigned to be 0.6 when $\mathrm{Re}$ is $10^{1} \sim 10^{2}[25,26]$. The momentum equation of the droplet is

$$
m_{d} g-k_{d} v^{2}=m_{d} \frac{\mathrm{d} v}{\mathrm{~d} t}=m_{d} v \frac{\mathrm{d} v}{\mathrm{~d} x}
$$


Integrating the Equation (3), the vertical velocity $v$ can be given as

$$
v^{2}=\frac{m_{d} g}{k_{d}}+C \exp \left(-\frac{2 k_{d} x}{m_{d}}\right)
$$

The constant $C$ is determined by the initial vertical velocity boundary condition of the droplet. According to the experimental results by Sheppard [23], sprinklers direct droplets into the hemispherical space below. Thus the maximum vertical velocity and minimum vertical velocity are initiated by droplets traveling directly downwards below the sprinkler and droplets traveling horizontally, respectively. Sheppard also concluded that the velocity of a droplet at $0.2 \mathrm{~m}$ below the sprinkler is approximately $0.4 \sim 0.6$ times $\sqrt{2 p_{d} / 10^{-6} \rho_{d}}$, with an average value of 0.5 taken here. For those droplets with a velocity direction when leaving the sprinkler of vertically downward, the constant $C$ is deduced from Equation (4) to be

$$
C_{\text {vert }}=\left[\left(0.5 \sqrt{\frac{2 p_{d}}{10^{-6} \rho_{d}}}\right)^{2}-\frac{m_{d} g}{k_{d}}\right] / \exp \left(-\frac{2 k_{d} x_{0}}{m_{d}}\right)
$$

and $x_{0}=0.2 \mathrm{~m}$. The constant $C$ for droplets having only a horizontal velocity is $C_{\text {hor }}=-\left(m_{d} g / k_{d}\right)$ which can be calculated from $x_{0}=0 \mathrm{~m}$ and $v_{x 0}=0 \mathrm{~m} / \mathrm{s}$ [25]. Then the maximum vertical velocity and minimum vertical velocity at the same $x$ coordinate are

$$
\begin{aligned}
& v_{\text {max }}=\sqrt{\frac{m_{d} g}{k_{d}}+C_{\text {vert }} \exp \left(-\frac{2 k_{d} x}{m_{d}}\right)} \\
& v_{\text {min }}=\sqrt{\frac{m_{d} g}{k_{d}}\left[1-\exp \left(-\frac{2 k_{d} x}{m_{d}}\right)\right]}
\end{aligned}
$$

Consequently, the actual vertical velocity of each droplet at a specified $x$ coordinate should be between $v_{\max }$ and $v_{\min }$, shown as $v_{\max }>v>v_{\min }$.

The envelope curve of the spray region is approximately parabolic according to NFPA13HB [27] and the external shape is defined as

$$
y^{2}=E x
$$

Thus, the horizontal cross section area of the spray region at coordinate $x$ is

$$
S(x)=\pi E x
$$


Sprinkler manufacturer information and experimental observations indicate that the wetted area at $3 \mathrm{~m}$ below the ceiling is a circle with radius approximately $3 \mathrm{~m}[27,28]$, i.e., $E=3$. Since the water flow density distribution is assumed to be uniform over the cross section area [25,29], the droplet number $n(x)$ in the sub-volume of the smoke layer column element with a small height of $\mathrm{d} x$ at coordinate position $x$ is then expressed as

$$
n(x)=\frac{\dot{M}}{m_{d} S(x) v} \mathrm{~d} x
$$

and

$$
\dot{M}=\frac{\rho_{d} K \sqrt{10 p_{d}}}{60 \times 10^{3}}
$$

where $K$ is taken to be $80 \mathrm{~L} /(\min \cdot \sqrt{\mathrm{bar}})$ for the sprinkler with nozzle diameter of $12.7 \mathrm{~mm}$ [23,27]. Using Equation (1) and (10), the drag force of the droplets on the smoke layer column element at coordinate $x$ is then deduced to be

$$
D^{\prime}(x)=n(x) D(x)=\frac{k_{d} \dot{M}}{m_{d} S(x)} v \mathrm{~d} x=\frac{\dot{M}}{S(x)} \times \frac{k_{d}}{m_{d}} \sqrt{\frac{m_{d} g}{k_{d}}+C \exp \left(-\frac{2 k_{d} x}{m_{d}}\right)} \mathrm{d} x
$$

where

$$
\frac{k_{d}}{m_{d}}=\left[\frac{\frac{1}{8} \rho_{g}(x) C_{D} \pi d_{d}^{2}}{\frac{1}{6} \rho_{d} \pi d_{d}^{3}}\right]=\frac{3 \rho_{g}(x) C_{D}}{4 \rho_{d} d_{d}}
$$

The diameters of different droplets $d_{d}$ are assumed to be same with a mean diameter $d_{m}$ here, which is calculated from Equations (14)-(16) [23,28]:

$$
\begin{gathered}
d_{m}=C_{m} d_{n} W e^{-1 / 3} \\
W e=\frac{\rho_{d} U^{2} d_{n}}{\sigma_{w}} \\
U=\frac{\dot{M}}{\rho_{d} \pi d_{n}^{2} / 4}
\end{gathered}
$$

where the surface tension of water $\sigma_{w}$ is taken to be $72.8 \times 10^{-3} \mathrm{~N} / \mathrm{m}$ and the coefficient $C_{m}$ is taken to be 2.33 for a sprinkler with nozzle diameter of $12.7 \mathrm{~mm}[23,30,31]$. 
Using Equation (12) and as shown in Figure 1, the total drag force of the sprinkler spray droplets to the smoke layer column element with unit area $\delta \Delta$ is

$$
D_{x_{1}}=\int_{x_{1}}^{h} D^{\prime}(x)=\int_{x_{1}}^{h}\left[\frac{\dot{M}}{S(x)} \times \frac{k_{d}}{m_{d}} \sqrt{\frac{m_{d} g}{k_{d}}+C \exp \left(-\frac{2 k_{d} x}{m_{d}}\right)}\right] \mathrm{d} x
$$

Substituting Equation (9) and Equation (13) into Equation (17) gives

$$
D_{x_{1}}=\int_{x_{1}}^{h}\left[\frac{\dot{M}}{\pi E x} \times \frac{3 \rho_{g}(x) C_{D}}{4 \rho_{d} d_{m}} \sqrt{\frac{4 \rho_{d} d_{m} g}{3 \rho_{g}(x) C_{D}}+C \exp \left(-\frac{6 \rho_{g}(x) C_{D} x}{4 \rho_{d} d_{m}}\right)}\right] \mathrm{d} x
$$

The constant $C$ in Equations (12), (17) and (18) would vary with different $x$ coordinates due to different initial vertical velocity boundary conditions of different droplets. To simplify the calculation, an assumption of the maximum drag force and the minimum drag force on the smoke layer column element were developed with the velocity $v_{\max }$ and $v_{\min }$ from Equations (6) and (7) so that

$$
\begin{gathered}
D_{x_{1}(\max )}=\int_{x_{1}}^{h}\left[\frac{\dot{M}}{S(x)} \times \frac{k_{d}}{m_{d}} \sqrt{\frac{m_{d} g}{k_{d}}+C_{\text {vert }} \exp \left(-\frac{2 k_{d} x}{m_{d}}\right)}\right] \mathrm{d} x \\
D_{x_{1}(\min )}=\int_{x_{1}}^{h} \frac{\dot{M}}{S(x)} \sqrt{\frac{k_{d} g}{m_{d}}\left[1-\exp \left(-\frac{2 k_{d} x}{m_{d}}\right)\right]} \mathrm{d} x
\end{gathered}
$$

which corresponds to the relation that $D^{\prime}(x)$ varies linearly with $v$, as shown in Equation (12). The actual value of $D_{x_{1}}$ should be between $D_{x_{1}(\max )}$ and $D_{x_{1}(\min )}$. An average value is taken to represent the drag force, which is then

$$
D_{x_{1}}=\frac{D_{x_{1}(\max )}+D_{x_{1}(\min )}}{2}
$$

\section{Velocity of Smoke Venting without Sprinkler Spray}

A fire room with a roof vent and make-up air inlet near the floor is shown in Figure 2(a). The pressure difference at the location of roof vent and make-up air inlet is expressed respectively as [32]

$$
\begin{gathered}
\Delta P_{I N-\text { OUT }}=\left(H-H_{N}\right)\left(\rho_{a}-\rho_{g, \text { unsprk }}\right) g \\
\Delta P_{\text {OUT-IN }}=\left(H_{N}-H_{L}\right)\left(\rho_{a}-\rho_{g, \text { unsprk }}\right) g
\end{gathered}
$$


(a)

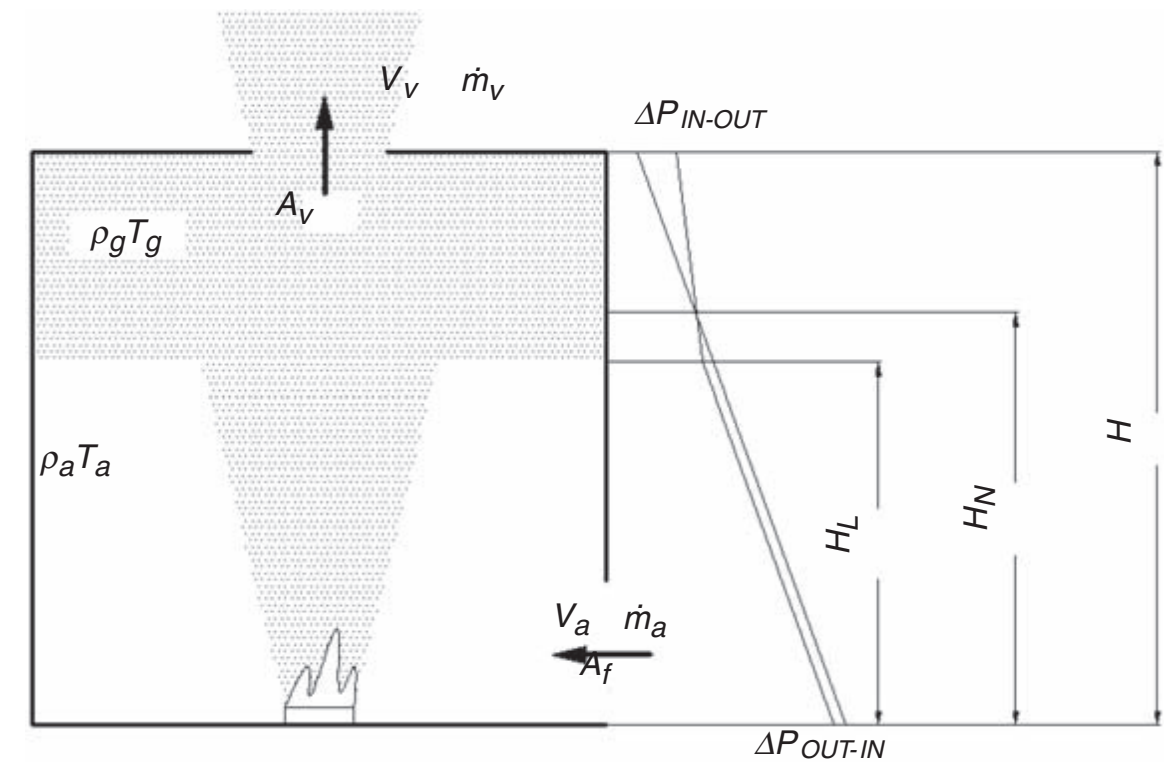

(b)

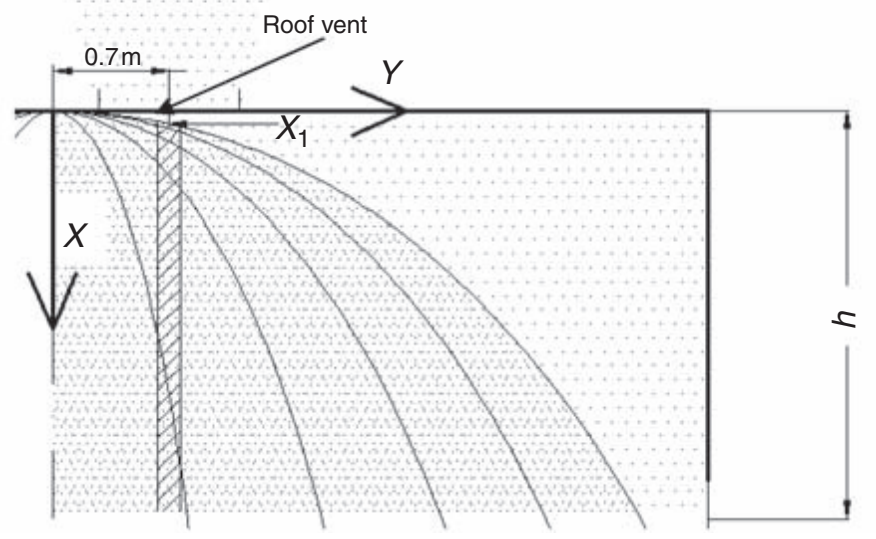

Figure 2. Schematic view of smoke venting: (a) smoke venting without sprinkler spray, (b) smoke venting under sprinkler spray.

where $\rho_{g}$, unsprk is the density of the smoke layer without a sprinkler spray. The velocity of smoke venting and make-up air is deduced to be as follows:

$$
\begin{gathered}
V_{V}=\sqrt{\frac{2 \Delta P_{I N-O U T}}{\rho_{g, \text { unsprk }}}}=\sqrt{\frac{2\left(H-H_{N}\right)\left(\rho_{a}-\rho_{g, \text { unsprk }}\right) g}{\rho_{g, \text { unsprk }}}} \\
V_{a}=\sqrt{\frac{2 \Delta P_{\text {OUT-IN }}}{\rho_{a}}}=\sqrt{\frac{2\left(H_{N}-H_{L}\right)\left(\rho_{a}-\rho_{g, \text { unsprk }}\right) g}{\rho_{a}}}
\end{gathered}
$$


Thus the mass flows are

$$
\begin{gathered}
\dot{m}_{V}=C_{d} A_{V} \rho_{g, \text { unsprk }} V_{V}=C_{d} A_{V} \rho_{g, \text { unsprk }} \sqrt{\frac{2\left(H-H_{N}\right)\left(\rho_{a}-\rho_{g, \text { unsprk }}\right) g}{\rho_{g, \text { unsprk }}}} \\
\dot{m}_{a}=C_{d} A_{f} \rho_{a} V_{a}=C_{d} A_{f} \rho_{a} \sqrt{\frac{2\left(H_{N}-H_{L}\right)\left(\rho_{a}-\rho_{g, \text { unsprk }}\right) g}{\rho_{a}}}
\end{gathered}
$$

where $C_{d}$ is taken to be 0.61 as recommended by Cooper [2]. Conservation of mass leads to

$$
\dot{m}_{V}=\dot{m}_{a}
$$

Substituting Equation (28) with Equation (26) and (27) gives

$$
A_{V} \sqrt{\rho_{g, \text { unsprk }}\left(H-H_{N}\right)}=A_{f} \sqrt{\rho_{a}\left(H_{N}-H_{L}\right)}
$$

The height of the neutral plane is then deduced to be

$$
H_{N}=\frac{A_{V}^{2} \rho_{g, \text { unsprk }} H+A_{f}^{2} \rho_{a} H_{L}}{A_{V}^{2} \rho_{g, \text { unsprk }}+A_{f}^{2} \rho_{a}}
$$

From this equation, $H_{N}$ approximately equals $H_{L}$ when $A_{V} \ll A_{f}$, which is referred to as the condition where the make-up area is much greater that the venting area. Defining $h=H-H_{L}$, the velocity of smoke venting is expressed as

$$
V_{V}=\sqrt{\frac{2 h\left(\rho_{a}-\rho_{g, \text { unsprk }}\right) g}{\rho_{g, \text { unsprk }}}}
$$

Since the smoke could be assumed to be an ideal gas, Equation (31) is converted to

$$
V_{V}=\sqrt{\frac{2 h\left(T_{g}-T_{a}\right) g}{T_{a}}}=\sqrt{\frac{2 h \overline{\Delta T} g}{T_{a}}}
$$

\section{Volumetric Flow of Smoke Venting with Sprinkler Spray}

The pressure difference which leads to smoke venting is weakened by the sprinkler spray drag force. In the conservation equation of momentum, both 
the pressure and the drag force are the source terms, which eventually determine the movement of the smoke [33]. Therefore, the pressure difference $\Delta P_{I N-O U T}$ in Equation (22) is revised to

$$
\Delta P_{I N-O U T}^{\prime}=\Delta P_{I N-O U T}-D_{x 1}
$$

Since the cooling effect of sprinkler spray on the smoke venting efficiency is not explicitly considered in this model, the temperature or density of the smoke layer after sprinkler cooling is used to calculate the pressure difference such that the density of smoke layer $\rho_{g}$, unsprk is replaced by $\rho_{g}$, sprk . As shown in Figure 2(b), the drag force on the smoke layer column element located beneath the center of the smoke vent is chosen to represent the entire effect of the sprinkler spray beneath the vent. The volumetric flow of smoke venting under the influence of a sprinkler spray is then

$$
W=C_{d} A_{V} V_{V}=C_{d} A_{V} \sqrt{\frac{2\left[h\left(\rho_{a}-\rho_{g, s p r k}\right) g-D_{x 1}\right]}{\rho_{g, s p r k}}}
$$

The intention is that the model is appropriate to situations where there is a stable layer and a roof vent within the spray region. It is unlikely the model could be applied to cases in which fire gases form part of a plume and is unnecessary where the smoke vents are remote from the spray region because there are no sprinkler droplets to initiate drag.

\section{EXPERIMENTS}

The experimental set up, shown in Figure 3, consisted of two parts; the burning cabin and the sprinkler cabin. The burning cabin was $4 \mathrm{~m}$ long, $2 \mathrm{~m}$ wide and $2.5 \mathrm{~m}$ high. Six air supply intakes each with a $0.8 \mathrm{~m} \times 0.4 \mathrm{~m}$ opening were located on both sides of the cabin. Diesel fuelled pool fires were located in the burning cabin to generate an initial smoke layer in the upper part of the sprinkler cabin. The sprinkler cabin was a cube with identical length, width, and height dimensions of $4.2 \mathrm{~m}$. A draft curtain with depth of $2.0 \mathrm{~m}$ was installed to maintain an initial stable smoke layer thickness of $2.0 \mathrm{~m}$. Make-up air was supplied under the curtains such that $A_{f}$ in the model is the area of the lower opening part of sprinkler cabin. A $4.2 \mathrm{~m}$ high gauge was placed in front of the cabin to measure the depth of the downward smoke plume as shown in Figure 3(b) and a digital video camera was used to record the experiments.

An open ZSTP-15 Copper Alloy spray sprinkler with a nozzle diameter of $12.7 \mathrm{~mm}$ and a flow coefficient of $80 \mathrm{~L} /(\mathrm{min} \cdot \sqrt{\mathrm{bar}})$ was used for 

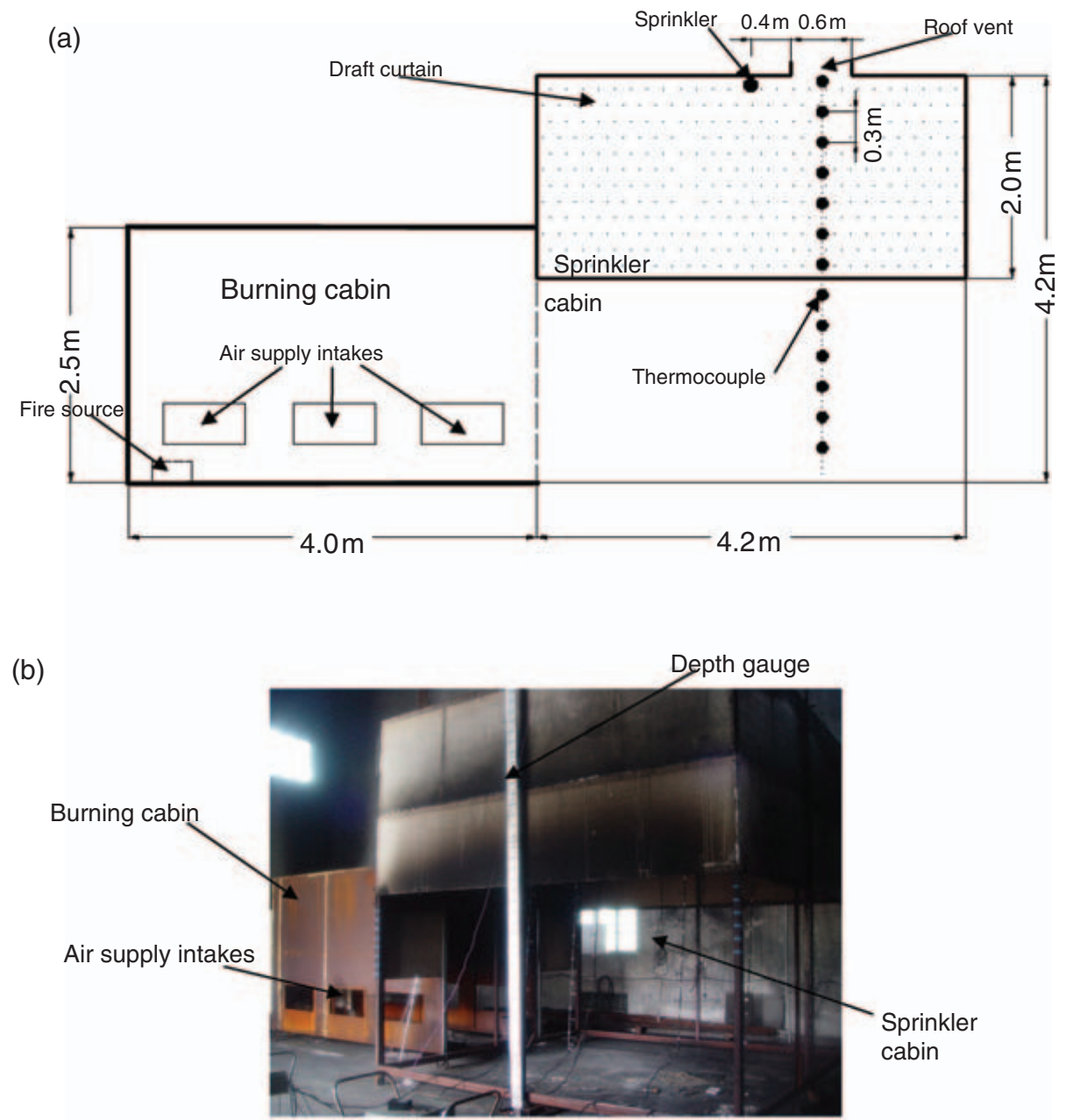

Figure 3. Experimental rig: (a) schematic view, (b) Photo. (The color version of this figure is available online.)

the experiments. The sprinkler was installed in the center of the sprinkler cabin roof in a pendant orientation. A pressure reducing valve and pressure transducer were installed in the pipeline to control the sprinkler operating pressure with an accuracy of $0.002 \mathrm{MPa}$. The spray envelope can be calculated by using Equation (8) such that when $x$ equals the $2 \mathrm{~m}$ height of the smoke curtain bottom, $y$ is $2.45 \mathrm{~m}$. Since the smoke curtain was horizontally $2.1 \mathrm{~m}$ or further away from the sprinkler, a small proportion of the droplet envelope was likely to be blocked by the smoke curtain. The horizontal momentum of the blocked droplets would be significantly reduced after traveling $2.1 \mathrm{~m}$. Consequently, very few droplets were likely to reflect back to the center of the spray region after hitting the smoke curtain. Instead, most of blocked droplets attach the curtain and fall vertically down to the floor as was observed during the experiments. 
As shown in Figure 4, two different adjacent roof vent configurations were used in the experiment. Experiments with one roof vent were conducted to validate the mathematical model. Experiments with three adjacent roof vents were conducted to investigate the effect of smoke venting

(a)

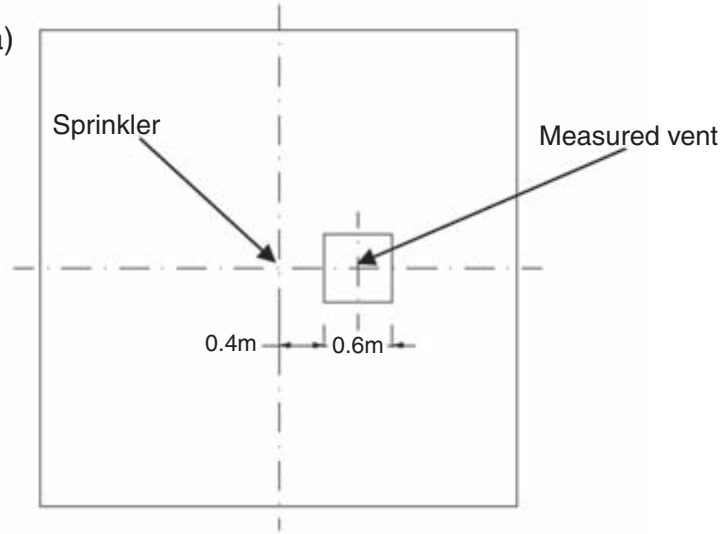

(b)

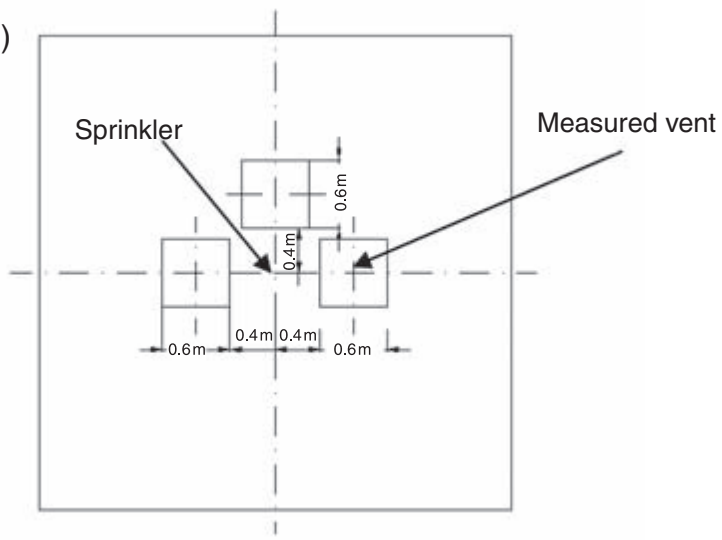

(c)

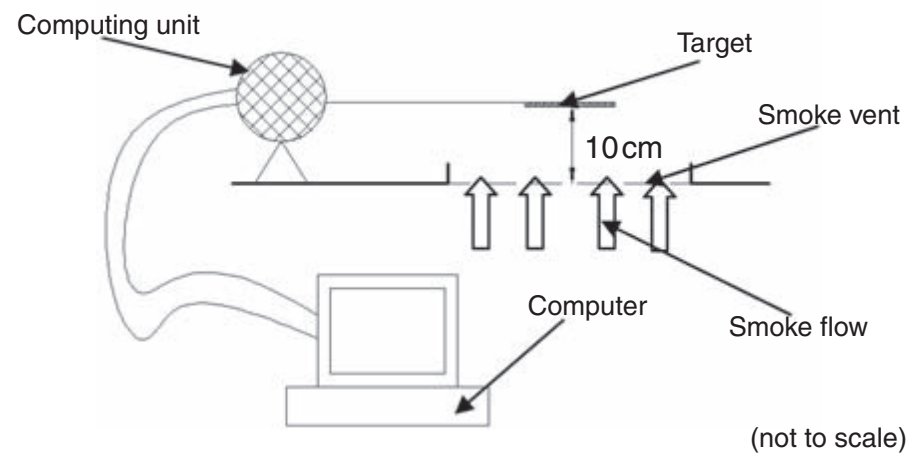

Figure 4. Configuration of smoke vents: (a) single roof vent, (b) three roof vents, (c) target flowmeter. 
area. The temperature of smoke was measured by thermocouple trees installed under the center of each vent. The vertical interval of the thermocouples was $0.3 \mathrm{~m}$. Thermocouples were covered by steel saddle waterproofing caps to prevent the water droplets from directly hitting the instruments.

A target flowmeter (see mechanism in [34]) was used to measure the volumetric flow of the vented smoke. This flowmeter senses the drag force generated by the momentum of the flow and converts it into flow rate in terms of the vent section area. The target element of the flowmeter was at the center of the vent (labeled as the 'Measured Vent' in Figure 4) to the right of the sprinkler. To avoid the effect of upward moving droplets, the probe was elevated $100 \mathrm{~mm}$ vertically from the vent plane as shown in Figure 4(c). To obtain the average flow a relatively large flat target element, $300 \times 300 \times 0.3 \mathrm{~mm}^{3}$ thick, was used as the velocity of the smoke flow was not uniform across the vent plane. The target element caused a pressure loss which reduced the flow during experiments by $8 \%$, as determined by a manufacturer's calibration [35,36]. Using this result, the flow magnitude without the presence of the target blockage could be computed.

A total of 36 experiments were conducted with two different pool fires; a $0.6 \mathrm{~m} \times 0.6 \mathrm{~m}$ pool and a $0.8 \mathrm{~m} \times 0.8 \mathrm{~m}$ pool. The heat release rate of the pool fires was determined by the mass loss rate measured by an electronic balance and the calorific value of the diesel which was taken to be $42,000 \mathrm{~kJ} / \mathrm{kg}$. Previous research using the cabin [37] determined the burning efficiency of the diesel to be 0.8 and as a result the heat release rates used in experiments were calculated to be $248 \mathrm{~kW}$ and $476 \mathrm{~kW}$ for the smaller and larger pools respectively. The total burning time of each experiment was about $300 \mathrm{~s}$. Two experiments were conducted without a sprinkler spray present. In experiments where the sprinkler was operated, the water spray was manually activated when the upper part of the sprinkler cabin was filled with a stable smoke layer. Fixed sprinkler operating pressures ranging between 0.03 and $0.15 \mathrm{MPa}$ were selected for the experiments.

The purpose of using a sprinkler cabin was to create a stable smoke layer which has a measurable depth and temperature rise. However the experiments were limited by the size of the cabin such that the smoke curtains were in close proximity to the sprinkler spray envelope and smoke vents. As a result, the movement of air around the periphery of the spray envelope might have been affected by the smoke curtains. This experimental arrangement does not ideally represent most real situations in which many sprinklers and smoke vents would be remote from smoke curtains. However, one specific application of this setup is the "cabin concept' [38,39] design. 


\section{RESULTS AND DISCUSSION}

\section{Smoke Venting without Sprinkler Spray}

The upper part of the sprinkler cabin filled with smoke after which the smoke started to flow out of the cabin through the bottom edge of the draft curtain. The smoke venting volumetric flow, with a smoke layer depth of $2 \mathrm{~m}$, reached its peak at $50 \sim 60 \mathrm{~s}$ for the $476 \mathrm{~kW}$ fire whereas the peak time for the $248 \mathrm{~kW}$ fire was around $80 \mathrm{~s}$. As shown in Figure 5, the measured peak volumetric flow values were $1761 \mathrm{~m}^{3} / \mathrm{h}$ and $1970 \mathrm{~m}^{3} / \mathrm{h}$ for the small and large fires respectively. For comparison, the calculated values were $1615 \mathrm{~m}^{3} / \mathrm{h}$ and $2544 \mathrm{~m}^{3} / \mathrm{h}$. If there were no sprinkler spray, the volumetric flow did not change significantly during the experiment. The temperature profiles measured in experiments with no sprinkler spray are plotted in Figure 6 . The temperatures at the ceiling are $65^{\circ} \mathrm{C}$ and $140^{\circ} \mathrm{C}$ for different
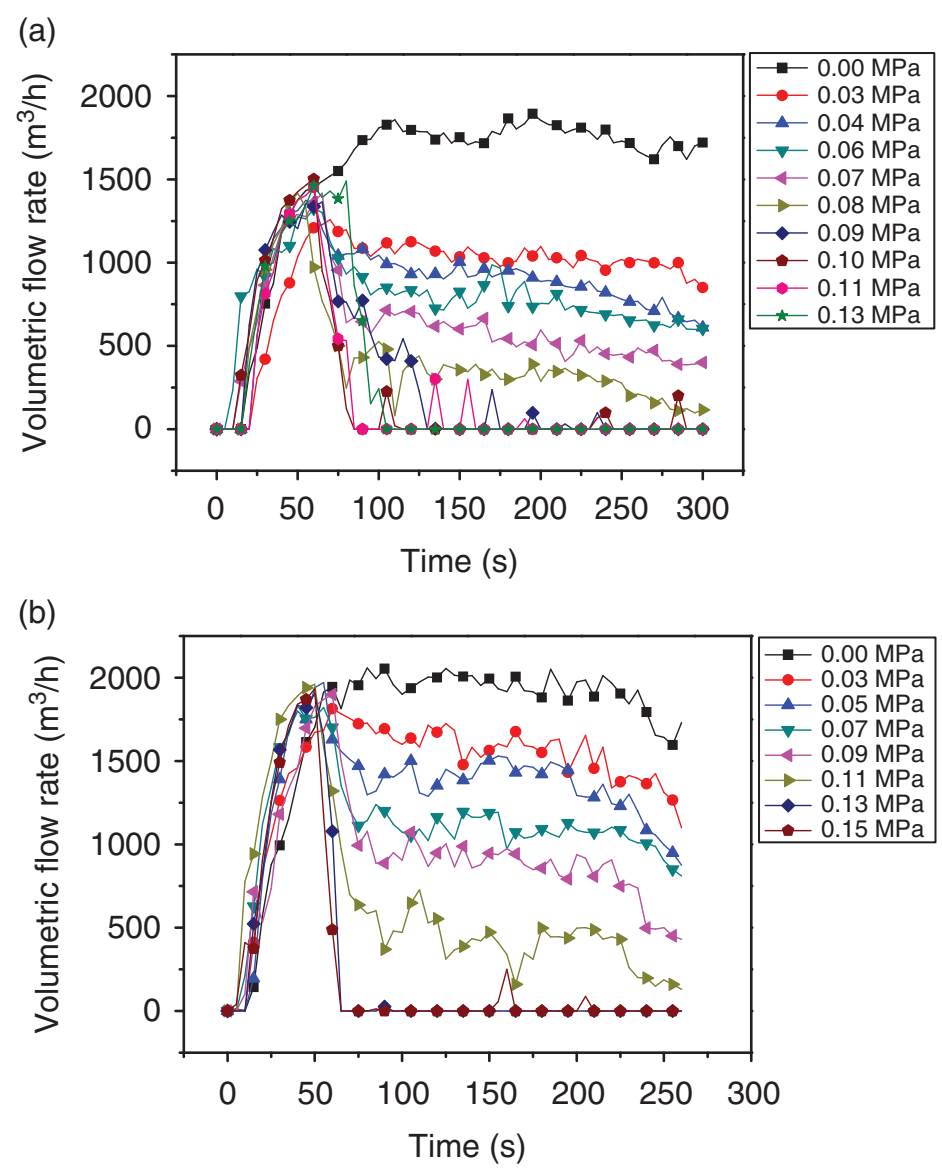

Figure 5. Volumetric flow measured in experiment series PF and PH: (a) experiment series PF $(248 \mathrm{~kW})$, (b) experiment series $\mathrm{PH}(476 \mathrm{~kW})$. (The color version of this figure is available online.) 
heat release rates, which are appropriate for the activation of sprinklers at typical temperature ratings for most applications.

\section{Smoke Venting with Sprinkler Spray}

After sprinkler operation, droplets of sprinkler spray cooled the smoke layer and decreased its buoyancy through their drag force. Consequently, sprinkler operation led to a decrease in the volumetric flow compared to experiments without a sprinkler spray. The volumetric flow of smoke venting with sprinkler spray was measured by the target flowmeter and the results are shown in Figure 5. The volumetric flow reached around $1490 \mathrm{~m}^{3} / \mathrm{h}$ and $1950 \mathrm{~m}^{3} / \mathrm{h}$ before the sprinkler was operated for the small and large fires respectively. The volumetric flow decreased sharply within $0.5 \mathrm{~min}$ after the sprinkler operated. After this its value remained
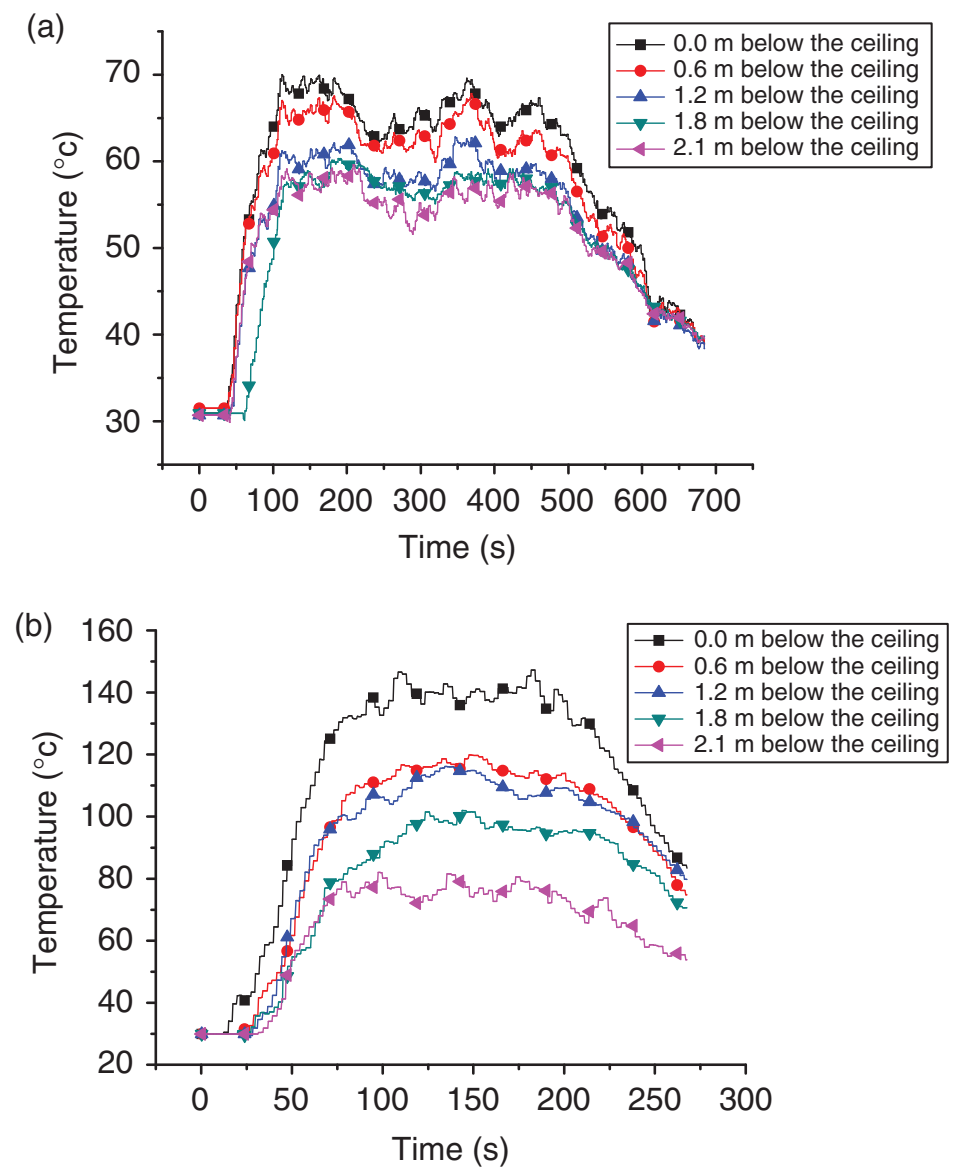

Figure 6. Temperature profile measured in experiments without sprinkler spray: (a) experiment PFO (248 kW), (b) experiment PHO $(476 \mathrm{~kW})$. (The color version of this figure is available online.) 
relatively stable and this period is regarded as the steady state smoke venting under sprinkler spray phase. When the fuel began to run out the smoke venting volumetric flow began to decrease to zero and the start of this phase was at about $250 \mathrm{~s}$ in the $248 \mathrm{~kW}$ experiments and $200 \mathrm{~s}$ in the $476 \mathrm{~kW}$ experiments.

The steady state volumetric flow was found to decrease as the sprinkler operating pressure was increased. For the $248 \mathrm{~kW}$ experiments the steady state volumetric flow was about $1000 \mathrm{~m}^{3} / \mathrm{h}$ when the operating pressure was $0.03 \mathrm{MPa}$ and decreased to $0 \mathrm{~m}^{3} / \mathrm{h}$ when the operating pressure was increased to $0.09 \mathrm{MPa}$. As shown in Figure 5(a), when the operating pressure was higher than $0.09 \mathrm{MPa}$, no smoke flowed through the vent at steady state under sprinkler spray. This condition is referred to here as 'ineffective smoke venting'. The sprinkler operating pressure at which ineffective smoke venting began is referred to as the 'critical ineffective smoke venting pressure'. Therefore, the critical ineffective smoke venting pressures in the $248 \mathrm{~kW}$ and $476 \mathrm{~kW}$ experiments were 0.09 and $0.13 \mathrm{MPa}$, respectively as shown in Figure 5.

Experimental data are summarized in Table 1, with the calculated smoke venting volumetric flow labeled as $W$ and the time averaged measured steady state volumetric flow labeled as $W_{M}$. As the standard working condition for the target flowmeter was $298 \mathrm{~K}$, the value of $W_{M}$ was revised because of the change in smoke density. The revised volumetric flow was calculated from

$$
W_{R}=\sqrt{\frac{\rho_{0}}{\rho_{g}}} W_{M}=\sqrt{\frac{T_{g}}{T_{0}}} W_{M}
$$

where $\rho_{0}$ and $\rho_{g}$ are density of smoke at $298 \mathrm{~K}\left(T_{0}\right)$ and the measured temperature $\left(T_{g}\right)$, respectively. The volumetric flow calculated from the model, Equation (34), is compared with $W_{R}$ in Figure 7 where the error bars on the experimental data show the maximum and minimum flow measured during the steady state period. According to the mathematical model, with the increase of the operating pressure and thus the discharge mass flow $\dot{M}$, the cooling effect and the drag force $D_{x 1}$ of the sprinkler spray increases, which leads to a decrease in pressure difference at the roof vent and therefore a decrease of smoke venting volumetric flow. This trend is in accordance with what was measured as shown in Figure 7. However, the calculated values are lower than the experimental values likely due to the nonuniformity of the drag force in the smoke venting region, which has been taken as uniform in the model by representing the drag force of smoke layer column element at the center. The volumetric flow calculated by using Equation (34) without considering the drag effect $D_{x 1}$ has also been 
Table 1. Summary of experiments.

\begin{tabular}{|c|c|c|c|c|c|c|c|c|c|c|}
\hline $\begin{array}{l}\text { Expt. } \\
\text { index }\end{array}$ & $\begin{array}{l}\text { Pool } \\
\text { size } \\
\left(\mathrm{m}^{2}\right)\end{array}$ & $\begin{array}{c}\text { Number } \\
\text { of } \\
\text { vents }\end{array}$ & $\begin{array}{c}\text { Expt. } \\
\text { no. }\end{array}$ & $\begin{array}{l}\text { HRR } \\
\text { (kW) }\end{array}$ & $\begin{array}{c}\text { Sprinkler } \\
\text { operating } \\
\text { pressure } \\
\text { (MPa) }\end{array}$ & $\begin{array}{l}\text { Ambient } \\
\text { temperature } \\
\text { (K) }\end{array}$ & $\begin{array}{c}\text { Average } \\
\text { temperature } \\
\text { rise } \\
\text { of smoke } \\
\text { layer }(\mathrm{K})\end{array}$ & $\underset{\left(\mathrm{m}^{3} / \mathrm{h}\right)}{W_{M}}$ & $\begin{array}{c}W_{R} \\
\left(\mathrm{~m}^{3} / \mathrm{h}\right)\end{array}$ & $\begin{array}{c}W \\
\left(m^{3} / h\right)\end{array}$ \\
\hline \multirow[t]{11}{*}{ PF } & 0.36 & 1 & PFO & 248 & None & 304 & 32.3 & 1762 & 1852 & 1615 \\
\hline & & & PF1 & 248 & 0.03 & 304 & 13.6 & 1050 & 1077 & 920 \\
\hline & & & PF2 & 248 & 0.04 & 304 & 10.2 & 920 & 944 & 712 \\
\hline & & & PF3 & 248 & 0.05 & 304 & 10.0 & 876 & 900 & 635 \\
\hline & & & PF4 & 248 & 0.06 & 304 & 8.5 & 811 & 830 & 434 \\
\hline & & & PF5 & 248 & 0.07 & 304 & 7.7 & 570 & 583 & 208 \\
\hline & & & PF6 & 248 & 0.08 & 304 & 7.2 & 329 & 336 & 0 \\
\hline & & & PF7 & 248 & 0.09 & 304 & 6.0 & 13 & 14 & 0 \\
\hline & & & PF8 & 248 & 0.10 & 304 & 5.8 & 7 & 7 & 0 \\
\hline & & & PF9 & 248 & 0.11 & 304 & 5.3 & 15 & 15 & 0 \\
\hline & & & PF10 & 248 & 0.13 & 304 & 4.9 & 0 & 0 & 0 \\
\hline \multirow[t]{10}{*}{$P G$} & 0.36 & 3 & PG1 & 248 & 0.03 & 301 & 12.3 & 825 & 846 & - \\
\hline & & & PG2 & 248 & 0.04 & 301 & 9.5 & 808 & 825 & - \\
\hline & & & PG3 & 248 & 0.05 & 301 & 8.4 & 800 & 815 & - \\
\hline & & & PG4 & 248 & 0.06 & 301 & 6.8 & 762 & 775 & - \\
\hline & & & PG5 & 248 & 0.07 & 301 & 6.5 & 548 & 557 & - \\
\hline & & & PG6 & 248 & 0.08 & 301 & 6.6 & 324 & 329 & - \\
\hline & & & PG7 & 248 & 0.09 & 301 & 5.9 & 119 & 121 & - \\
\hline & & & PG8 & 248 & 0.10 & 301 & 5.5 & 22 & 23 & - \\
\hline & & & PG9 & 248 & 0.11 & 301 & 5.3 & 0 & 0 & - \\
\hline & & & PG10 & 248 & 0.13 & 301 & 4.8 & 0 & 0 & - \\
\hline \multirow[t]{8}{*}{$\mathrm{PH}$} & 0.64 & 1 & $\mathrm{PHO}$ & 476 & None & 303 & 80.9 & 1970 & 2236 & 2544 \\
\hline & & & $\mathrm{PH} 1$ & 476 & 0.03 & 303 & 30.0 & 1595 & 1686 & 1468 \\
\hline & & & $\mathrm{PH} 2$ & 476 & 0.05 & 303 & 25.9 & 1431 & 1503 & 1286 \\
\hline & & & $\mathrm{PH} 3$ & 476 & 0.07 & 303 & 16.5 & 1103 & 1142 & 855 \\
\hline & & & $\mathrm{PH} 4$ & 476 & 0.09 & 303 & 12.8 & 909 & 935 & 517 \\
\hline & & & PH5 & 476 & 0.11 & 303 & 11.2 & 442 & 453 & 0 \\
\hline & & & PH6 & 476 & 0.13 & 303 & 9.9 & 0 & 0 & 0 \\
\hline & & & $\mathrm{PH} 7$ & 476 & 0.15 & 303 & 10.3 & 0 & 0 & 0 \\
\hline \multirow[t]{7}{*}{ PI } & 0.64 & 3 & $\mathrm{Pl} 1$ & 476 & 0.03 & 300 & 16.8 & 1336 & 1377 & - \\
\hline & & & $\mathrm{Pl} 2$ & 476 & 0.05 & 300 & 13.3 & 1157 & 1186 & - \\
\hline & & & PI3 & 476 & 0.07 & 300 & 12.5 & 948 & 971 & - \\
\hline & & & PI4 & 476 & 0.09 & 300 & 12.0 & 775 & 792 & - \\
\hline & & & PI5 & 476 & 0.11 & 300 & 11.0 & 428 & 437 & - \\
\hline & & & PI6 & 476 & 0.13 & 300 & 10.2 & 32 & 33 & - \\
\hline & & & $\mathrm{Pl} 7$ & 476 & 0.15 & 300 & 9.8 & 0 & 0 & - \\
\hline
\end{tabular}

- not calculated.

plotted in Figure 7. A dashed line is drawn to represent the volumetric flow without sprinkler spray. The difference between the dashed line and the curve considering only cooling effect indicates the contribution of cooling to the reduction of volumetric flow. Similarly, the total effect of the sprinkler 

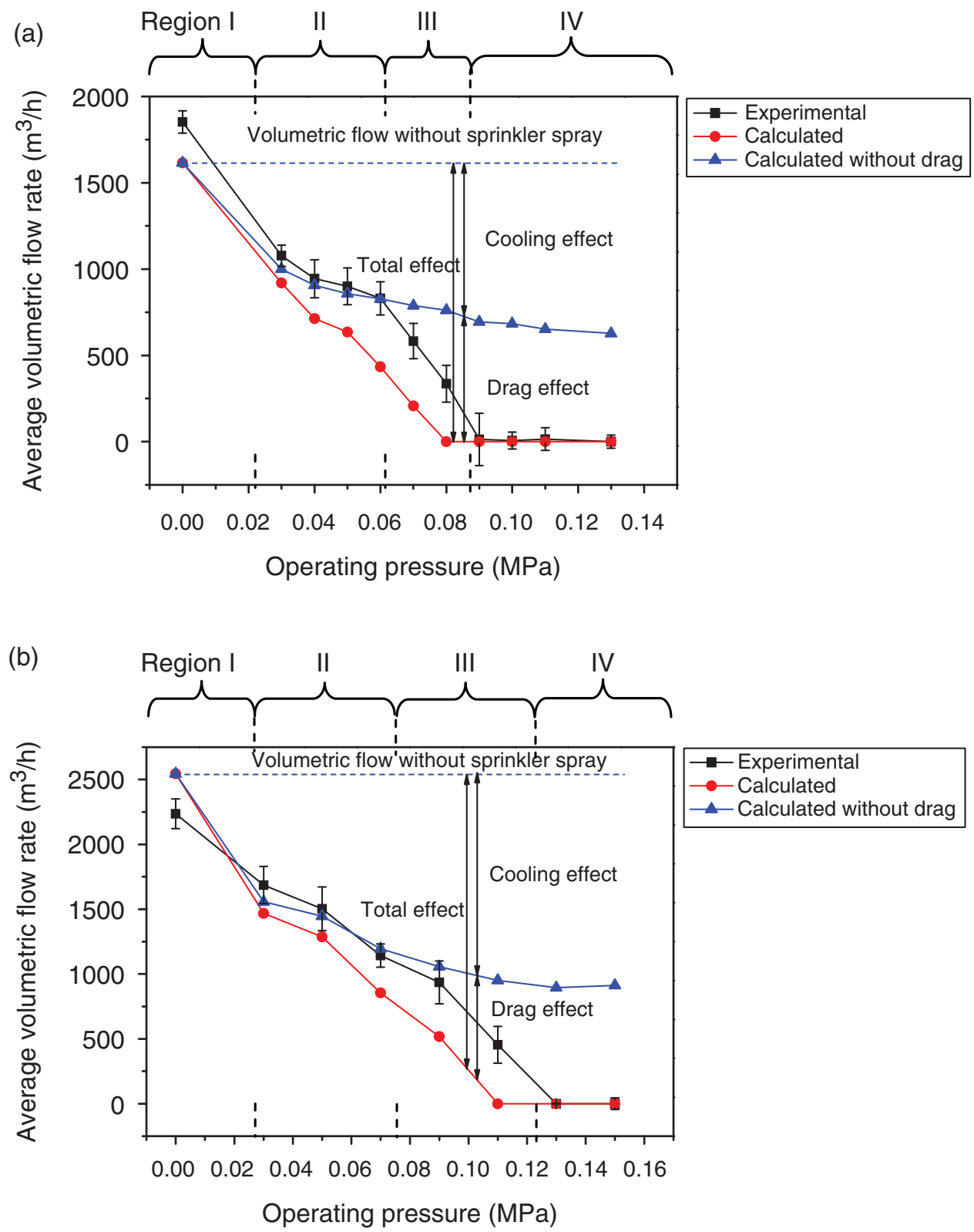

Figure 7. Experimental and calculated volumetric flow of smoke venting with increase of $p_{d}$ : (a) experiment series PF, (b) experiment series PH. (The color version of this figure is available online.)

spray, which includes both cooling and drag, is regarded as the difference between the dashed line and the curve calculated by Equation (34) as labeled in Figure 7. Therefore, the drag effect can be calculated by subtracting the cooling contribution from the total effect. In order to compare the merits of the models with and without drag Figure 7 is divided into four regions of interest in which the percentage of the model experiment difference over the 
measured volumetric flow without sprinkler spray is calculated. In region I, where there is no sprinkler spray, the models give a $13 \%$ under- or overprediction compared to the experiment values in series $\mathrm{PF}$ and $\mathrm{PH}$, respectively. The model with only cooling gives a more accurate result in region II where the operating pressures are $0.03-0.06 \mathrm{MPa}$ in series $\mathrm{PF}$ and 0.03-0.07 MPa in series PH. The errors calculated by the model with only cooling are less than 5\% while the model with cooling and drag gives an error of $9-20 \%$. In this region, both models under-predict the volumetric flow except for experiment $\mathrm{PH} 3$ in which the model with only cooling gives an over-predicted value with an error of $3 \%$. However, as the operating pressure reaches region III, the prediction of model without drag starts to significantly change. The error increases from $11 \%$ and $8 \%$ in series PF and $\mathrm{PH}$, respectively to eventually reach $23 \%$. On the other hand, the errors given by model with drag stay at $18-20 \%$. Note that the model without drag gives an overestimated result in this region while the prediction of model with drag is still underestimated. The error given by the model without drag keeps increasing until it reaches $40 \%$ in region IV where the operating pressures are equivalent or greater than the 'critical ineffective smoke venting pressure'. On the other hand the model with drag predicts the volumetric smoke flow to reach zero in this region.

As shown in Table 1, the temperature rise of the smoke layer below the vent is not $0 \mathrm{~K}$ at the critical ineffective smoke venting pressure or at higher pressures. For example in experiments PF7, PH6, and PH7, the temperature rises are $6.0,9.9$, and $10.3 \mathrm{~K}$ respectively. This implies that smoke layer buoyancy can still exist during the occurrence of ineffective smoke venting. Therefore, it can be concluded that the drag force plays an important role in adjacent ineffective smoke venting besides any cooling effect. As the operating pressure increased to the critical ineffective smoke venting pressure, the drag effect exceeds the buoyancy of the smoke which leads to ineffective smoke venting. Ineffective smoke venting has been predicted by the mathematical model and is also found in the experiment, although the predicted critical ineffective venting pressures of 0.08 and $0.11 \mathrm{MPa}$ are slightly lower than the equivalent experimental values for the two fire sizes.

The pressure difference across the roof vent, which is caused by the buoyancy of the smoke layer, pushes the smoke upward and eventually leads to smoke venting. However the spray drag force will pull the smoke down and reduce the buoyant effect of the smoke layer. The spray drag force is determined by both the velocity and the quantity of droplets, which increase as the operating pressure increases. Consequently, as the operating pressure keeps increasing, the drag force is eventually greater than buoyancy, which leads to a flow downward rather than venting upward. 


\section{COMPARISON OF DIFFERENT SMOKE VENTING CONDITIONS}

The number of adjacent roof vents at the same distance from the sprinkler was increased to three in the experiment series PG and PI. The volumetric flow of smoke vented was recorded at the Measured Vent as shown in Figure 4(b). Although the total volumetric flow of smoke was not measured directly, it was likely to be on the order of three times that recorded at the measured vent. The values of $W_{R}$ obtained with different numbers of vents are compared in Figure 8. Before ineffective smoke venting is initiated, the volumetric flow measured at the measured vent under the three vent condition is less than the volumetric flow under a single vent condition. As the sprinkler operating
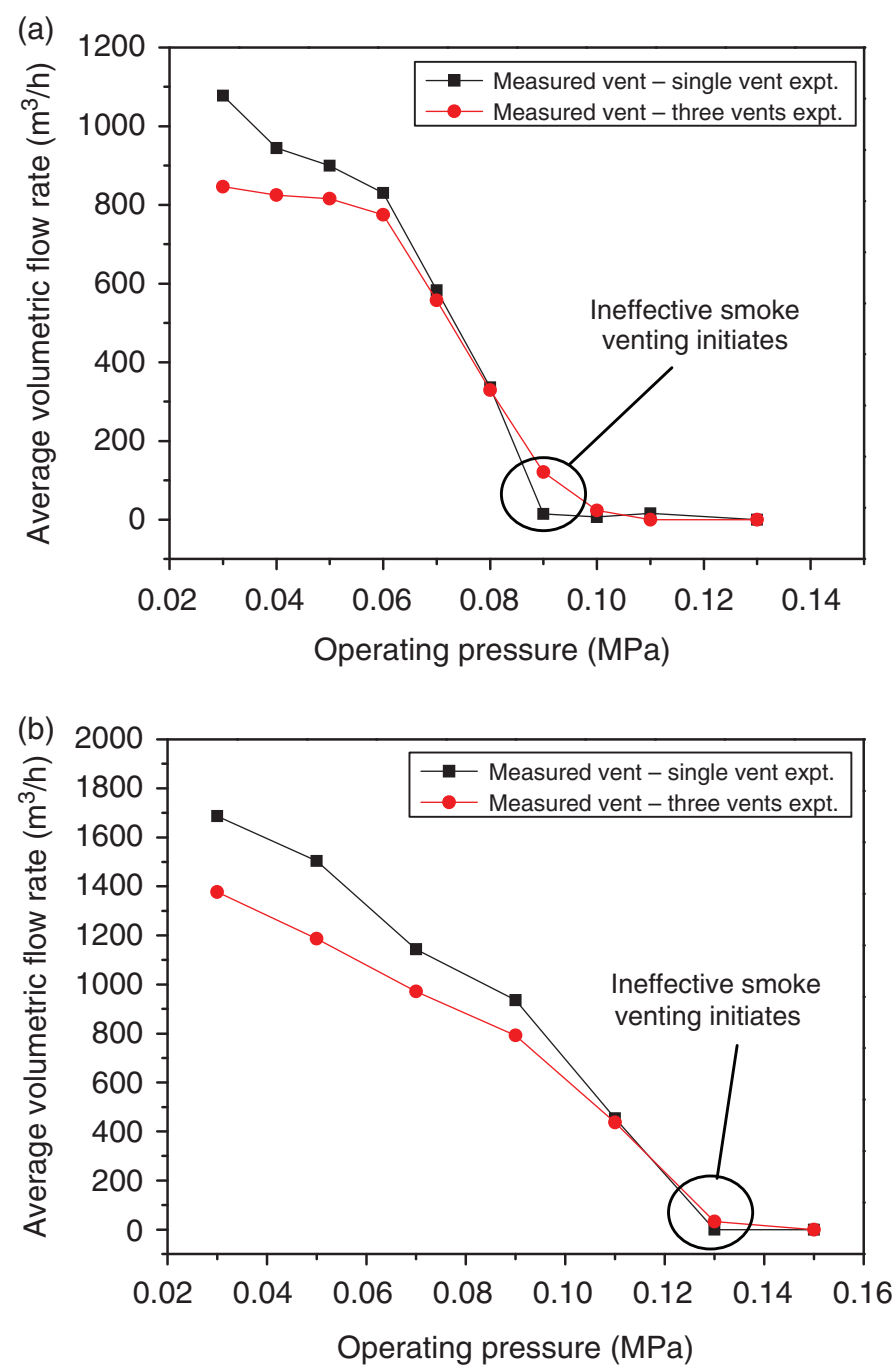

Figure 8. Volumetric flow of smoke venting under different smoke venting conditions: (a) comparison of volumetric flow in experiment series PF and PG, (b) comparison of volumetric flow in experiment series $\mathrm{PH}$ and $\mathrm{Pl}$. (The color version of this figure is available online.) 
pressure increases the difference between the two volumetric flow values decreases. The ineffective smoke venting pressure with three vents was $0.09 \mathrm{MPa}$ for the $248 \mathrm{~kW}$ experiments and $0.13 \mathrm{MPa}$ for the $476 \mathrm{~kW}$ experiments and, as highlighted in Figure 8, these critical values for the two different vent areas gave similar results for the two fire sizes.

Figure 9 presents the average temperature rise of the smoke layer beneath the measured vent. The average temperature rises are different for the two vent areas before the smoke venting becomes ineffective. At the larger smoke vent area the total volumetric flow increased, thus leading to a decrease in the smoke temperature rise in the sprinkler cabin. The temperature rise difference decreased as the sprinkler operating pressure
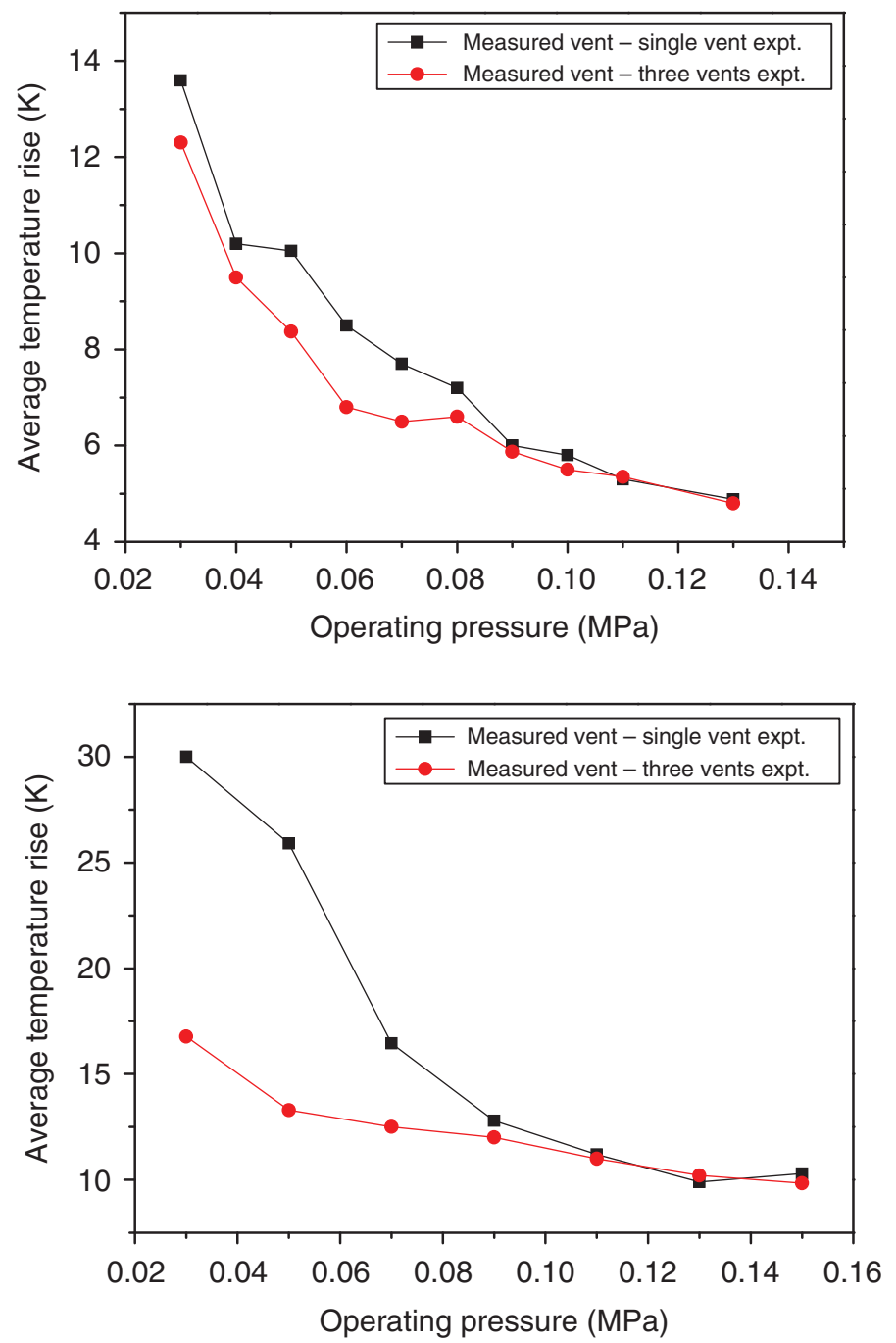

Figure 9. Smoke temperature rise under different smoke venting conditions: (a) comparison of smoke layer temperature rise in experiment series PF and PG, (b) comparison of smoke layer temperature rise in experiment series $\mathrm{PH}$ and $\mathrm{Pl}$. (The color version of this figure is available online.) 
K. Y. LI ET AL.

(a)

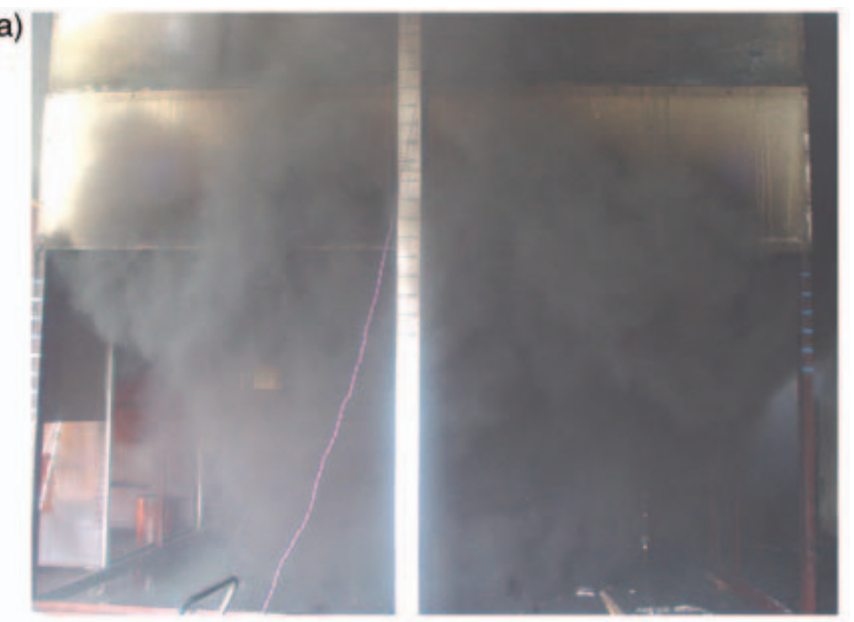

(b)

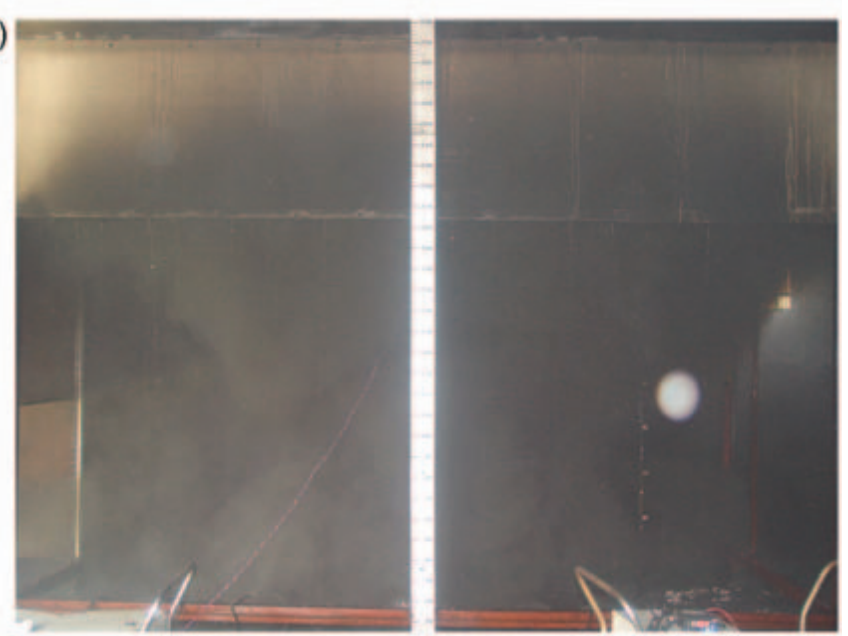

Figure 10. Smoke flow field under ineffective smoke venting: (a) experiment $\mathrm{PH} 7$, (b) experiment PI7. (The color version of this figure is available online.)

increased and almost reached zero at the critical ineffective smoke venting pressure. Intuitively, it might be expected that the smoke vent area would affect the smoke venting efficiency prior to achieving ineffective conditions which would lead to different volumetric flow and temperature rises. However when smoke venting is ineffective, the vent area would not affect the smoke dragged down by the sprinkler spray, which would lead to an identical critical ineffective venting pressure and temperature rise. So it can be concluded that smoke venting area would have an insignificant impact on the smoke flow field during ineffective smoke venting as the vents have lost their venting function. The flow fields of smoke would be very similar under ineffective smoke venting conditions no matter how large the smoke vent area is. Figure 10 shows the smoke flow field in experiments PH7 and PI7 which are during ineffective smoke venting conditions. It can be seen that 

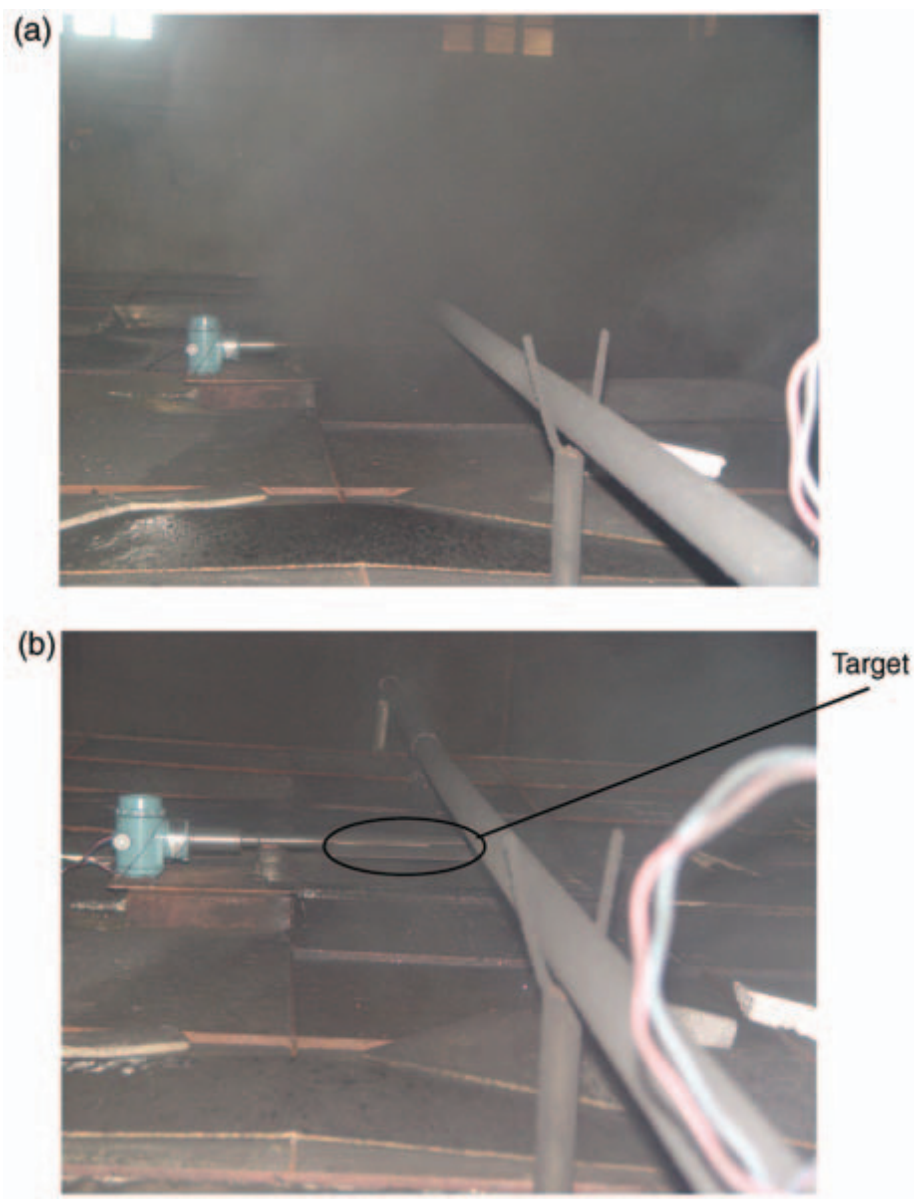

Figure 11. Photographs of smoke venting state change under ineffective smoke venting (experiment PF10): (a) before sprinkler operation, (b) after sprinkler operation. (The color version of this figure is available online.)

the smoke is pulled down and flows out from the lower part of sprinkler cabin whilst no smoke flowed out through the roof vents in these two experiments. Therefore, the smoke venting condition had no significant effect on the smoke flow. As seen in the experiments with ineffective smoke venting such as experiment PF10 in Figure 11, the smoke venting prior to the activation of the sprinkler spray causes a plume through the vent such that the target flowmeter could not be seen. After the sprinkler was operated, no smoke flowed out through the roof vent so that the measuring probe can be very clearly seen.

\section{CONCLUSIONS}

A new mathematical model has been developed to investigate the effect of a sprinkler spray on adjacent horizontal smoke venting by calculating the 
drag force of sprinkler spray and accounting for the buoyancy of the smoke layer. Full-scale experiments have been carried out to validate the mathematical model. The predictions of the mathematical model show that as the sprinkler operating pressure increases, the volumetric flow of smoke venting decreases. In contrast to previous research, this study increased the sprinkler operating pressure up to values which were high enough to cause the smoke to no longer flow through the vent. The smoke venting function of the roof vent is lost at a certain sprinkler operating pressure referred to as the 'critical ineffective venting sprinkler pressure' which causes 'ineffective smoke venting'. Ineffective smoke venting is the situation in which the volumetric flow reaches $0 \mathrm{~m}^{3} / \mathrm{h}$; i.e., no smoke flows out through the roof vents. The volumetric flow of vented smoke predicted by the mathematical model underestimates the volumetric flow with a stable error of $9-20 \%$ compared to the experimental data up until ineffective smoke venting'. The predictions are lower likely due to the nonuniformity of drag force at smoke venting region which has been ignored in the mathematical model.

Different smoke vent areas were considered in the experiments. Ineffective smoke venting is confirmed by the experimental data which has shown that the smoke vent areas would lead to different volumetric flows and smoke layer temperature rises prior to ineffective smoke venting. The critical ineffective smoke venting pressure is almost unchanged if the vent area is increased and the area of the vent has no significant effect on the smoke flow field under ineffective smoke venting conditions.

The mathematical model reveals the mechanism of smoke venting adjacent to a sprinkler spray and predicts smoke venting efficiency at the roof vent. This model can be applied to the prediction of smoke venting behavior near a sprinkler spray in fire simulation tools, such as a zone fire model, where the average temperature of the smoke layer is computed.

\section{NOMENCLATURE}

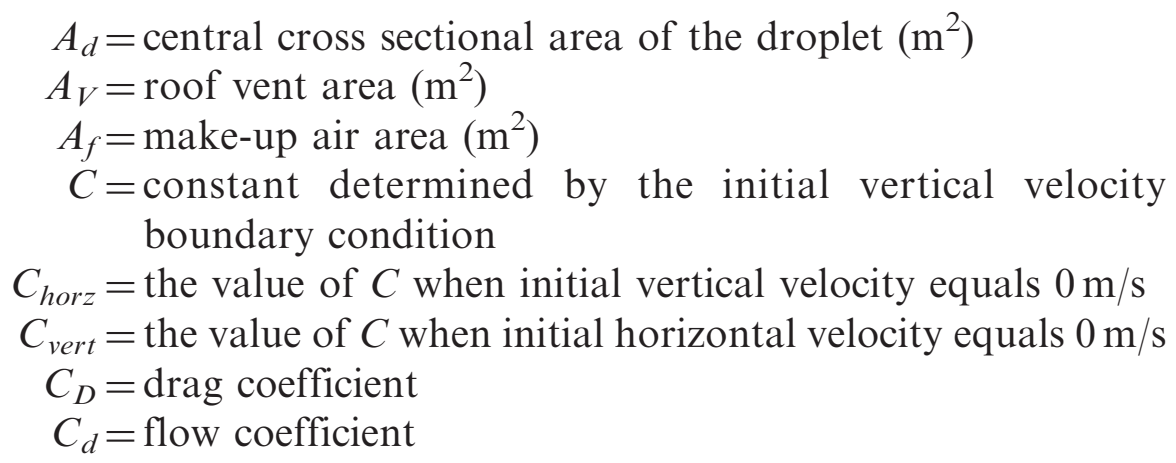


$C_{m}=$ coefficient for calculating the mean droplet diameter

$d_{d}=$ diameter of the droplet $(\mathrm{m})$

$d_{m}=$ mean diameter of all droplets $(\mathrm{m})$

$d_{n}=$ diameter of the sprinkler nozzle $(\mathrm{m})$

$D(x)=$ vertical drag force of a single water droplet at coordinate (N)

$D^{\prime}(x)=$ drag force of unit volume at coordinate $\left(\mathrm{N} / \mathrm{m}^{3}\right)$

$D_{x 1}=$ total drag force on smoke layer column element with unit area $\left(\mathrm{N} / \mathrm{m}^{2}\right)$

$D_{x_{1}(\max )}=$ maximum drag force assumed $\left(\mathrm{N} / \mathrm{m}^{2}\right)$

$D_{x_{1}(\min )}=$ minimum drag force assumed $\left(\mathrm{N} / \mathrm{m}^{2}\right)$

$E=$ coefficient of equation for the external shape of the spray region

$g=$ acceleration due to gravity $\left(\mathrm{m} / \mathrm{s}^{2}\right)$

$h=$ initial depth of the smoke layer (m)

$H=$ height of the room (m)

$H_{L}=$ height of the smoke layer interface (m)

$H_{N}=$ height of the neutral plane (m)

$k_{d}=$ coefficient for calculating $D(x)(\mathrm{m} / \mathrm{s})$

$K=$ flow coefficient of the sprinkler $\mathrm{L} /(\min \cdot \sqrt{\mathrm{bar}})$

$m_{d}=$ mass of droplet $(\mathrm{kg})$

$\dot{m}_{V}=$ mass flow of smoke venting $(\mathrm{kg} / \mathrm{s})$

$\dot{m}_{a}=$ mass flow of make-up air $(\mathrm{kg} / \mathrm{s})$

$\dot{M}=$ discharge mass flow of the sprinkler nozzle $(\mathrm{kg} / \mathrm{s})$

$n(x)=$ water droplet numbers in unit volume at coordinate $x$

$p_{d}=$ operating pressure of the sprinkler $(\mathrm{MPa})$

$\Delta P_{I N-O U T}=$ pressure difference at the vent $(\mathrm{Pa})$

$\triangle P_{\text {OUT-IN }}=$ pressure difference of the make-up air $(\mathrm{Pa})$

$\Delta P_{I N-O U T}^{\prime}=$ pressure difference at the vent under sprinkler spray $(\mathrm{Pa})$

$S(x)=$ area of horizontal cross section of the spray region at coordinate $x\left(\mathrm{~m}^{2}\right)$

$t=$ time of droplet travel (s)

$\overline{\Delta T}=$ average temperature rise of the smoke layer $(\mathrm{K})$

$T_{g}=$ average smoke layer temperature $(\mathrm{K})$

$T_{a}=$ ambient temperature $(\mathrm{K})$

$U=$ initial velocity of water when discharging out of sprinkler nozzle $(\mathrm{m} / \mathrm{s})$

$v=$ vertical velocity of the droplet $(\mathrm{m} / \mathrm{s})$

$v_{\max }=$ maximum vertical velocity of the droplet at coordinate $x(\mathrm{~m} / \mathrm{s})$

$v_{\min }=$ minimum vertical velocity of the droplet at coordinate $x(\mathrm{~m} / \mathrm{s})$

$V_{V}=$ velocity of smoke venting $(\mathrm{m} / \mathrm{s})$

$V_{a}=$ velocity of supply air $(\mathrm{m} / \mathrm{s})$ 
$W=$ calculated volumetric flow of smoke venting $\left(\mathrm{m}^{3} / \mathrm{h}\right)$

$W_{M}=$ measured volumetric flow of smoke venting $\left(\mathrm{m}^{3} / \mathrm{h}\right)$

$W_{R}=$ actual volumetric flow of smoke venting $\left(\mathrm{m}^{3} / \mathrm{h}\right)$

$W e=$ Weber number

$x=$ vertical coordinate from the spray origin $(\mathrm{m})$

$x_{1}=x$-coordinate of the apex of the smoke layer column element $(\mathrm{m})$

$y=$ horizontal coordinate from the spray origin $(\mathrm{m})$

\section{Greek symbols}

$$
\begin{aligned}
\rho_{a} & =\text { air density at ambient temperature }\left(\mathrm{kg} / \mathrm{m}^{3}\right) \\
\rho_{d} & =\text { density of water }\left(\mathrm{kg} / \mathrm{m}^{3}\right) \\
\rho_{g} & =\text { density of smoke layer }\left(\mathrm{kg} / \mathrm{m}^{3}\right) \\
\rho_{g, \text { sprk }} & =\text { density of smoke layer under sprinkler spray }\left(\mathrm{kg} / \mathrm{m}^{3}\right) \\
\rho_{g, \text { unsprk }} & =\text { density of the smoke layer without sprinkler spray }\left(\mathrm{kg} / \mathrm{m}^{3}\right) \\
\sigma_{w} & =\text { surface tension of water }(\mathrm{N} / \mathrm{m})
\end{aligned}
$$

\section{ACKNOWLEDGEMENTS}

This work was supported by the Natural Science Foundation of China, Grant No. 50904055 and the Opening Fund of the State Key Laboratory of Fire Science, University of Science and Technology of China, Grant No. HZ2008-KF06. Kai-Yuan Li is currently the Arup Fire Post-Doc Fellow at the University of Canterbury, NZ.

\section{REFERENCES}

1. Klote, J.H. and Milke, J.A., Design of Smoke Management Systems, American Society of Heating, Refrigerating and Air-Conditioning Engineers, Atlanta, GA, USA, 1992.

2. Cooper, L.Y., "Smoke and Heat Venting," In: SFPE Handbook of Fire Protection Engineering, 3rd edn, Chapter 3-9, National Fire Protection Association, Quincy, MA, USA, 2002 .

3. Heselden, A.J.M., The Interaction of Sprinkler and Roof Venting in Industrial Buildings: Current Knowledge, Building Research Establishment, Borehamwood, Herts, UK, 1984.

4. Beyler, C.L. and Cooper, L.Y., "Interaction of Sprinkler with Smoke and Heat Vents," Fire Technology, Vol. 37, 2001, pp. 9-35.

5. McGrattan, K.B., Hamins, A. and Stroup, D., Sprinkler, Smoke \& Heat Vent, Draft Curtain Interaction - Large Scale Experiments and Model Development, National Institute of Standards and Technology, Gaithersburg, MD, USA, 1998.

6. NFPA 13, Standard for the Installation of Sprinkler Systems, National Fire Protection Association, Quincy, MA, USA, 2002.

7. NFPA 231C, Standard for Rack Storage of Materials, National Fire Protection Association, Quincy, MA, USA, 2002. 
8. NFPA 204M, Guide for Smoke and Heat Venting, National Fire Protection Association, Quincy, MA, USA, 2002.

9. FMRC, Heat Vents and Fire Curtains: Effect on Operation of Sprinklers and Visibility, Factory Mutual Research Corporation, Norwood, MA, USA, 1956.

10. Thomas, P.H. and Hinkley, P.L., Design of Roof-venting Systems for Single-story Building, Technical Paper No. 10, Building Research Establishment, Fire Research Station (FRS), Borehamwood, Herts, UK, 1964.

11. Suchomel, M.R., A Preliminary Study of Factors Influencing the Use of Vents with Ordinary-Degree Sprinkler. Technical report, File NC449, Assignment 63K4340, Underwriters' Laboratories for the National Board of Fire Underwriters, Camas, WA, USA, July 1964.

12. Waterman, T.E., Foxx, C.E., Mniszewski, K.R. and Eacret, D.L., Fire Venting of Sprinklered Buildings. Technical Report, IITRI Project J08385, Chicago, Illinois Institute of Technology Research Institute, July 1982.

13. Hinkley, P.L., Hansell, G.O., Marshall, N.R. and Harrison, R., "Sprinklers and Vents Interaction- Experiments at Ghent," Fire Surveyor, October 1992, pp. 18-23.

14. Sheppard, D.T. and Steppan, D.R., Sprinkler, Heat \& Smoke Vent, Draft Curtain ProjectPhase 1 Scoping Tests, Technical Report, Underwriters Laboratories, Inc., Northbrook, IL, USA, May 1997.

15. Heselden, A.J.M., "Taking a New Look at Combining Sprinkler Systems with Venting," Fire, October 1985, pp. 42-43.

16. Hinkley, P.L., "The Effect of Vents on the Opening of the First Sprinklers," Fire Safety Journal, Vol. 11, 1986, pp. 211-225.

17. Hinkley, P.L., "The Effect of Smoke Venting on the Operation of Sprinklers Subsequent to the First," Fire Safety Journal, Vol. 14, 1989, pp. 221-240.

18. Chow, W.K. and Cheung, Y.L., "Simulation of Sprinkler-Hot Layer Interaction Using a Field Model," Fire and Materials, Vol. 18, 1994, pp. 359-379.

19. Cooper, L.Y., "The Interaction of an Isolated Sprinkler Spray and a Two-Layer Compartment Fire Environment: Phenomena and Model Simulations," Fire Safety Journal, Vol. 25, 1995, pp. 89-107.

20. Cooper, L.Y., "The Interaction of an Isolated Sprinkler Spray and a Two-Layer Compartment Fire Environment," International Journal of Heat and Mass Transfer, Vol. 38, 1995, pp. 679-690.

21. Ingason, H. and Olsson, S., Interaction between Sprinklers and Fire Vents. Technical Report, Swedish National Testing and Research Institute (SP), Boras, Sweden, 1992.

22. Persson, B. and Ingason, H., Modeling of Interaction between Sprinklers and Fire VentsPresent Knowledge, Technical Report, Swedish National Testing and Research Institute (SP), Boras, Sweden, 1996.

23. Sheppard, D.T., Spray Characteristics of Fire Sprinklers. PhD dissertation, Northwestern University, Evanston, IL, USA 2002.

24. Morgan, H.P., "Heat Transfer from a Buoyant Smoke Layer Beneath a Ceiling to a Sprinkler Spray-A Tentative Theory," Fire and Materials, Vol. 3, 1979, pp. 27-33.

25. Bullen, M.L., The Effect of a Sprinkler on the Stability of a Smoke Layer Beneath a Ceiling, Fire Research Note 1016, Fire Research Station, BRE, Borehamwood, Herts, UK, 1974.

26. Chow, W.K. and Yao, B., "Numerical Modeling for Interaction of a Water Spray with Smoke Layer," Numerical Heat Transfer, Vol. 39, 2001, pp. 267-283.

27. NFPA 13HB, Automatic Sprinkler System Handbook, National Fire Protection Association, Quincy, MA, USA, 2002.

28. Chow, W.K. and Shek, L.C., "Physical Properties of a Sprinkler Water Spray," Fire and Materials, Vol. 17, 1993, pp. 279-292. 
29. Li, K.Y., Hu, L.H., Huo, R., Li, Y.Z., Chen, Z.B., Sun, X.Q. and Li, S.C., "A Mathematical Model on Interaction of Smoke Layer with Sprinkler Spray," Fire Safety Journal, Vol. 44, 2009, pp. 96-105.

30. Yu, H.Z., "Investigation of Spray Patterns of Selected Sprinklers with the FMRC Drop Size Measuring System," pp. 1165-1176, In: Fire Safety Science - Proceedings of the First International Symposium. London, International Association for Fire Safety Science, 1986.

31. Chan, T.S., "Measurement of Water Density and Droplet Size Distributions of Selected ESFR Sprinklers," Journal of Fire Protection Engineering, Vol. 6, 1994, pp. 79-87.

32. Drysdale, D., An Introduction to Fire Dynamics, 2nd edn, Wiley, New York, 1999.

33. Chow, W.K. and Fong, N.K., "Numerical Simulation of Cooling of the Fire-induced Air Flow by Sprinkler Water Spray," Fire Safety Journal, Vol. 17, 1991, pp. 263-290.

34. Bela, L.G., Instrument Engineers' Handbook: Process Measurement and Analysis, 4th edn, CRC Press, USA, 2003.

35. Bolt, User Guide of SBL Target Flowmeter, (In Chinese), Xian, China, 2000.

36. Bolt, Introduction for Selection of SBL Target Flowmeter, (In Chinese), Xian, China, 2000.

37. Yi, L., Study on Smoke Movement and Management in Atrium Building. PhD dissertation, University of Science and Technology of China, Hefei, Anhui, China, 2005.

38. Beever, P., "Cabins and Islands: A Fire Protection Strategy for an International Airport Terminal Building," pp. 709-718, In: Fire Safety Science - Proceedings of the Third International Symposium. International Association for Fire Safety Science, London, 1991.

39. Chow, W.K., "On the 'Cabin' Fire Safety Design Concept in the New Hong Kong Airport Terminal Building," Journal of Fire Science, Vol. 15, 1997, pp. 404-423. 